\title{
IT Governance and Types of IT Decision Makers in German Hospitals
}

\section{An Empirical Study Among IT Decision Makers}

\author{
The study analyzes the current status of IT governance in German hospitals. The most \\ important requirements of IT managers for IT are the optimization and standardization of \\ processes. IT investments in German hospitals shift from administrative to medical IT \\ applications. Private hospitals display relatively higher IT budgets than do non-profit or \\ public hospitals. Two types of future IT decision makers are empirically identified. They \\ differ in their role as initiators for process optimization and regarding the degree of \\ involvement in strategic decision making.
}

DOI 10.1007/s12599-010-0132-6

\section{The Authors \\ Felix Köbler M.Sc. Jens Fähling M.Sc. Prof. Dr. Helmut Krcmar Lehrstuhl für Wirtschaftsinformatik Technische Universität München Boltzmannstr. 3 85748 Garching b. München Germany felix.koebler@in.tum.de jens.faehling@in.tum.de krcmar@in.tum.de url: http://www.winfobase.de}

Prof. Dr. Jan Marco Leimeister ( $\varangle$ ) Lehrstuhl für Wirtschaftsinformatik Universität Kassel Nora-Platiel-Straße 4 34127 Kassel Germany leimeister@uni-kassel.de

Received: 2009-12-09

Accepted: 2010-05-26

Accepted after two revisions by Prof. Dr. Buxmann.

Published online: $2010-10-28$
This article is also available in German in print and via http://www. wirtschaftsinformatik.de: Köbler $F$, Fähling J, Leimeister JM, Krcmar H (2010) IT-Governance und IT-Entscheidertypen in deutschen Krankenhäusern. Eine empirische Untersuchung unter Krankenhaus-IT-Leitern. WIRTSCHAFTSINFORMATIK. doi: 10.1007/s11576-010-0248-9.

(c) Gabler Verlag 2010

\section{Introduction}

In 2007, the German health care system amounted to approximately $€ 257$ billion for health services (Destatis 2009b), representing $10.6 \%$ of the gross domestic product (GDP) (Destatis 2009a) of the Federal Republic of Germany. Even in previous years, Germany was a member of the Top 10 in the OECD regarding per capita spending on health care (Anderson et al. 2006). According to the German health report of the Federal Statistical Office Germany (2009), expenses for the hospital sector amounted to a total of approximately $€ 64$ billion in 2007.

The appropriate utilization of information technology (IT) is increasingly important for the health care sector, especially in providing medical services (Jähn and Nagel 2004) and associated administrative processes (Lehmann 2005; Haas 2005). In cases, IT enables an increase in efficiency and effectiveness of processes for examination, treatment and management in hospitals (Hacker and Schommer 2004). Furthermore, the utilization of IT may offer strategic and competitive advantages (Piccoli and Ives 2005) and therefore opportunities for differentiation within the hospital sector.

Numerous studies show IT enabled improvements of business processes in health care, e.g., by IT applications for data capturing and handling, preparation of medication and administrative management (Raymond and Dold 2002; Crane and Raymond 2003). In the early 1990s, studies documented that the implementation of IT may result not only in cost savings by automating information gathering and processing, but also due to faster and improved provision of information for decision makers (Borzekowski 2002). It could be shown that an improvement of information provision for decision makers can result in higher quality of treatment (Apkon and Sighaviranon 2001; Hacker and Schommer 2004) and care (Nahm and Poston 2000).

Despite the economic importance of the health sector in general and the important role of hospitals within the health care sector, research on IT management in hospitals has hardly delivered sound data or explanatory models. Several recent studies are solely conceptual in nature and lack a review and test of theories by empirical data (Sachs 2005). Other studies focus on specific parts of IT management, such as decisions of investments 
and composition of budgets related to IT (Bernnat 2006; Blum and Schilz 2005); however, they do not employ robust statistical methods of analysis (Riedel 2006) and statistically significant and sound results due to low participation (Irving and Nevo 2005). In Germany, several studies were conducted in 2006 (Leimeister et al. 2008; Köbler et al. 2009) and in 2008 that focused on the state of IT management in hospitals using a broad empirical base in order to partly close the described gap.

The following analysis and results are based on the study conducted in 2008 . The research questions were derived from the IT Governance Framework developed by Weill and Ross (Weill 2004; Weill and Ross 2005, 2004) and its IT decision domains as a theoretical reference. In addition, different types of decision makers were described using multivariate analysis methods.

The rest of the paper is organized as follows: Sect. 2 gives an introduction to the theoretical foundation of IT governance frameworks and the research questions. Section 3 describes the research methodology and structure of the sample. In Sect. 4 the empirical results are discussed and summarized. Section 5 outlines limitations of the study and provides an outlook on future research.

\section{Theoretical Foundations}

\subsection{IT Governance}

The concept of IT governance as a specific field of corporate governance has evolved and been developed on the background of increased importance of IT in enterprises and businesses today (Meyer et al. 2003). A common definition of governance is the specification of 'who' is responsible for decisions and its corresponding results (Krcmar 2009). Corporate governance is concerned with the organization and control of management to bring about an appropriate definition of business objectives, and is concerned with a corporate policy that considers different interests of various stakeholders (Witt 2000). Consequently, IT governance is an important part of corporate governance.

According to Weill (2004), IT governance covers the whole framework for decision making and rights of participation as well as responsibilities to ensure the desired utilization of IT within a company. This approach is largely compatible with other IT governance approaches,

Table 1 IT decision domains according to Weill and Ross (2004)

\begin{tabular}{ll}
\hline IT decision domains & Description \\
\hline IT Principles & High-level statements about how IT is used in the busines \\
IT Architecture & $\begin{array}{l}\text { Organizing logic for data, applications, and infrastructure } \\
\text { captured in a set of policies, relationships, and technical } \\
\text { choices to achieve desired business and technical } \\
\text { standardization and integration }\end{array}$ \\
& $\begin{array}{l}\text { Centrally coordinated, shared IT services that provide the } \\
\text { foundation for the enterprise's IT capability }\end{array}$ \\
IT Infrastructure & $\begin{array}{l}\text { Specifying the business need for purchased or internally } \\
\text { developed IT applications }\end{array}$ \\
Business Application Needs & $\begin{array}{l}\text { Decisions about how much and where to invest in IT, } \\
\text { including project approvals and justification techniques }\end{array}$ \\
IT Investment and Prioritization &
\end{tabular}

such as the widely used approach CobiT (IT Governance Institute 2009). The IT Governance Framework (Weill 2004; Weill and Ross 2004, 2005) is the result of several empirical studies. These studies have revealed patterns of IT governance constellations of top performers. The framework encompasses five major decision domains which are summarized in Table 1.

Our study focused on the status quo of IT governance in German hospitals motivated by a lack of reliable empirical data on IT governance in German hospitals in literature.

\subsection{Reference Framework and Research Questions}

Our descriptive-exploratory study is based on the IT Governance Framework introduced by Weill and Ross (2005) that serves as a theoretical framework and systematization of formulated research questions. We developed our research questions together with representatives of industry associations and hospitals in several iterations. The research questions were derived from the IT decision domains (see Table 2). In a next step, several experts from each group of participants tested the questions regarding consistency and clarity with the help of pre-tests.

\section{Methodology}

A quantitative empirical survey of IT decision makers was conducted in German hospitals to answer our research questions. Our understanding of the term 'hospital' is based on the definition provided by the German Federal Statistical Office ( $\$ 2$ No. 1 and
$\$ \$ 3,5$ of Krankenhausfinanzierungsgesetzes (KHG) in conjunction with $\$ 107$ Sect. 1 (SGB V)). Accordingly, hospitals are "(...) facilities, in which, by medical and nursing assistance, diseases, disorders or physical injury should be cured or alleviated or obstetrics is given and the caregivers can be housed and fed" (Federal Statistical Office Germany 2005, translated from German). According to the German Federal Statistical Office, 2,086 hospitals were registered in Germany in 2008 (Destatis 2009c).

\subsection{Data Collection}

The data collection was divided into two steps: Preliminarily, we conducted ten semi-structured interviews (Bortz and Döring 2002) with experts working in the German health care sector or hospitals. Each interview lasted for two hours and included IT executives from hospitals of various sizes (four interviews), IT executives of insurance companies (two interviews) and representatives of leading manufacturers of hospital information systems (four interviews). In the second step, we used records of a commercially available address database (Deutsches Krankenhaus Adressbuch) to contact potential participants. As a part of the post-processing of data, we excluded double counting by multi-stage validation checks and incomplete data sets. All subsequent results are based on survey data provided by the participants, i.e. IT executives and technical directors.

\subsection{Sample Structure}

A total of 207 data sets could be collected by the survey. After post-processing of collected data, 206 were used for further analysis. This represents a response rate 
Table 2 IT Decision domains with assigned research questions of the empirical study

\begin{tabular}{lll}
\hline $\begin{array}{l}\text { IT decision domains (Weill and } \\
\text { Ross 2004) }\end{array}$ & $\begin{array}{l}\text { Extract from central questions by Weill and Ross } \\
(2004)\end{array}$ & Research questions of the empirical study \\
\hline IT Principles & What is the role of IT in the business? & $\begin{array}{l}\text { Are German hospitals able to survive without the } \\
\text { use of IT systems? } \\
\text { Should IT in German hospitals be considered } \\
\end{array}$ \\
& $\begin{array}{l}\text { solely from a cost perspective? } \\
\text { Does IT possess the ability to enable new and } \\
\text { profitable business models for German hospitals? } \\
\text { Does IT deliver value for German hospitals? }\end{array}$
\end{tabular}

IT Architecture

IT Infrastructure

Business Application Needs

IT Investment and Prioritization
What technical capabilities should be standardized enterprise-wide to support IT efficiencies and facilitate process standardization and integration?

What infrastructure services are most critical to achieving the enterprise's strategic objectives?

What are the market and business process opportunities for new business applications?

What are the distributions in the current and proposed IT portfolios?
Which organizational units or departments are involved in IT decisions affecting the entire hospital (IT standards)?

What administrative and medical processes and functions does IT currently support in German hospitals? Which will be supported in the future?

What tasks are provided by IT executives of German hospitals for their IT?

What opportunities in IT can be seen for the core business?

Which applications will be of relevance for future investment strategies?

How much say do IT executives have in investment decisions?

Table 3 Structure of data sample

${ }^{a}$ Differences to the sample result from missing data

\begin{tabular}{|c|c|c|c|c|c|}
\hline \multirow[t]{2}{*}{ Type of sponsorship } & \multicolumn{3}{|c|}{ Number of beds } & \multirow{2}{*}{$\begin{array}{l}\text { Total data } \\
\text { sample }\end{array}$} & \multirow{2}{*}{$\begin{array}{l}\text { Federal Health } \\
\text { Report } \\
(2009 a)\end{array}$} \\
\hline & $\begin{array}{l}200 \text { and less } \\
\text { beds }\end{array}$ & $\begin{array}{l}200 \text { to } 799 \\
\text { beds }\end{array}$ & $\begin{array}{l}800 \text { and } \\
\text { more beds }\end{array}$ & & \\
\hline Public & $6.00 \%$ & $24.50 \%$ & $10.00 \%$ & $40.50 \%$ & $31.93 \%$ \\
\hline $\mathrm{N}$ & 12 & 49 & 20 & 81 & 665 \\
\hline Private & $6.50 \%$ & $9.50 \%$ & $3.00 \%$ & $19.00 \%$ & $37.49 \%$ \\
\hline $\mathrm{N}$ & 13 & 19 & 6 & 38 & 781 \\
\hline Independent/Non-profit & $7.50 \%$ & $29.50 \%$ & $3.50 \%$ & $40.50 \%$ & $30.58 \%$ \\
\hline $\mathrm{N}$ & 15 & 59 & 7 & 81 & 637 \\
\hline Entire sample & $20.00 \%$ & $63.50 \%$ & $16.50 \%$ & $100.00 \%$ & \\
\hline $\mathrm{N}$ & 40 & 127 & 33 & $200^{\mathrm{a}}$ & \\
\hline $\begin{array}{l}\text { Federal Health Report } \\
(2009 b)\end{array}$ & $56.70 \%$ & $39.17 \%$ & $4.13 \%$ & $100.00 \%$ & $100.00 \%$ \\
\hline $\mathrm{N}$ & 1,181 & 816 & 86 & 2,083 & 2,083 \\
\hline
\end{tabular}

of $9.88 \%$. The majority of the participants $(88.2 \%)$ were male and $59.6 \%$ were aged between 35 and 50 years.

For a useful analysis of the data, a segmentation of participants on the basis of objective characteristics is required. Recognized categories for segmentation of hospitals are size, as measured by the number of beds, and type of sponsorship. A comparison of former studies reveals that there are no standardized categories for differentiating the size of hospitals. The Federal Statistical Office distinguishes six categories, whereas the German Hospital Institute distinguishes four (Blum and Schilz 2005). Surveys conducted by the Institute of Hospital Administration Braunschweig were based on six different categories (Riedel 2006). In the underlying study, hospitals were divided into the categories "less than 200 beds", "200-799 beds" and " 800 or more beds". This categorization was based on insights derived from the conducted ex- pert interviews and allows the application of statistical methods due to relatively balanced sample sizes.

In Germany, three possible types of sponsorships exist for hospital organizations: public, private and non-profit. Table 3 compares the structure of the data sample to the total population. The sample is not representative according to the Federal Health Report. The sample size of hospitals with less than 200 beds is under-represented; in contrast, 
Fig. 1 General perception of IT in German hospitals comparison according to type of sponsorship
Fig. 2 General perception of IT in German hospitals comparison according to perceived value proposition
To what extent do you agree with the following statements?

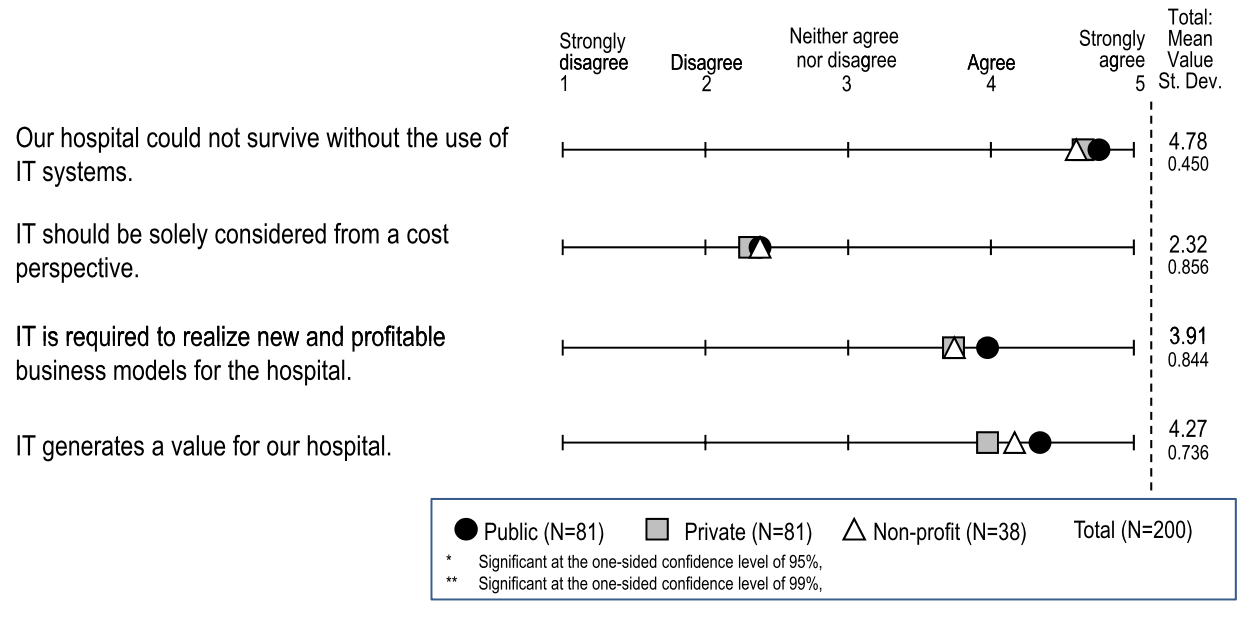

To what extent do you agree with the following statements?

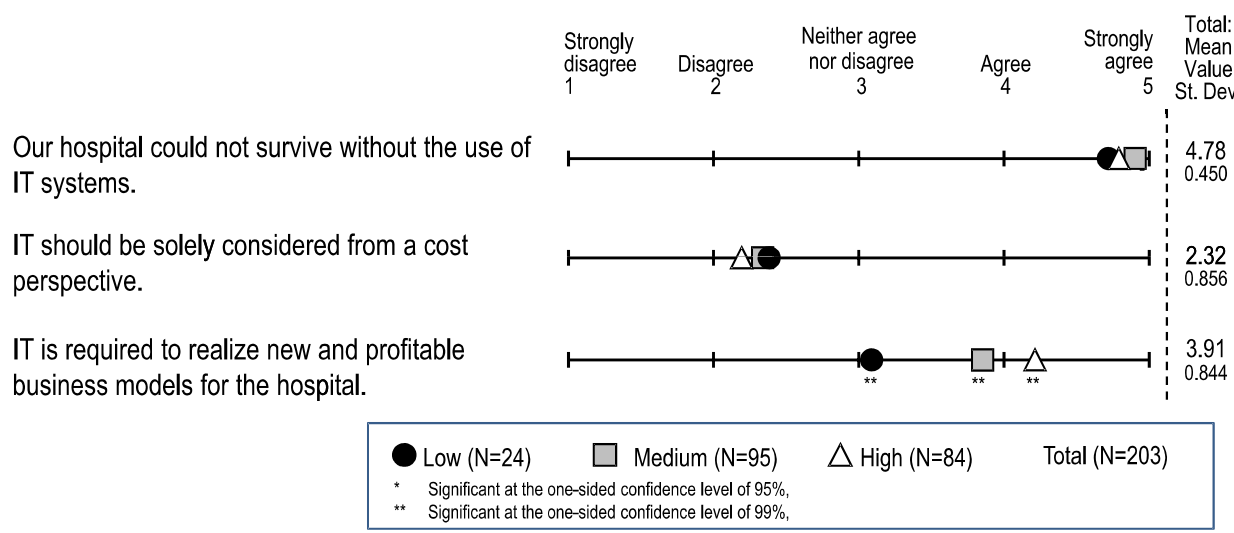

the medium and large hospitals are overrepresented. With regard to sponsorship, the sample contains too many public and non-profit hospitals in comparison to private hospitals. The category "public hospitals" includes local, urban, as well as university hospitals.

\section{Findings}

\subsection{General Perceptions of IT}

Participants were initially asked about their general perception of IT, specifically about the fundamental strategic importance of IT for their hospital, the role of IT for developing novel business models, as well as the importance of IT in their hospital. In addition, IT managers were queried about their perception of IT value contribution for the hospital organization. We detected that all participating IT executives regard IT as absolutely important for their hospital. The finding documents a high diffusion of IT in administrative as well as medical processes in German hospitals. This is in line with responses that IT is necessary for establishing new business models, and that IT provides value proposition for the hospital. All participants rejected the statement that IT should be solely considered from a cost perspective. Differences (based on $t$-tests) between hospitals with different types of sponsorships were not statistically significant (Fig. 1).

In a next step, the first three question items were analyzed and related to the variable "perceived value proposition". IT executives were divided into three groups based upon their perception of value proposition that IT afforded their hospital. If a participant evaluated the question item "IT delivers a value proposition for our hospital" by the three lowest values ("strongly disagree", "disagree" and "neither agree nor disagree") of the 5-point Likert scale, we classified the perception of IT value contribution as low. Members of the group medium rated the IT value contribution with "agree" and members of the group high with "strongly agree".
A division of the population according to the item "perceived value contribution of IT" in three groups (high, medium, low) resulted in statistically significant differences between these groups in rating the question item "We need IT to realize new and profitable business models for the hospital" (Fig. 2). Especially IT executives with a low perception of IT value contribution have a cautious view of the need for new and profitable business models. Our data indicate a strong positive correlation between the implementation of new and profitable business models in hospitals and the perception of the value contribution of IT by IT executives (Fähling et al. 2009). Significant deviations for the other two question items were not detected.

\subsection{IT Architecture}

Decisions about the global IT architecture in hospitals are often not made by IT management alone, but in conjunction with other stakeholders. Administrative as well as medical units/executives 


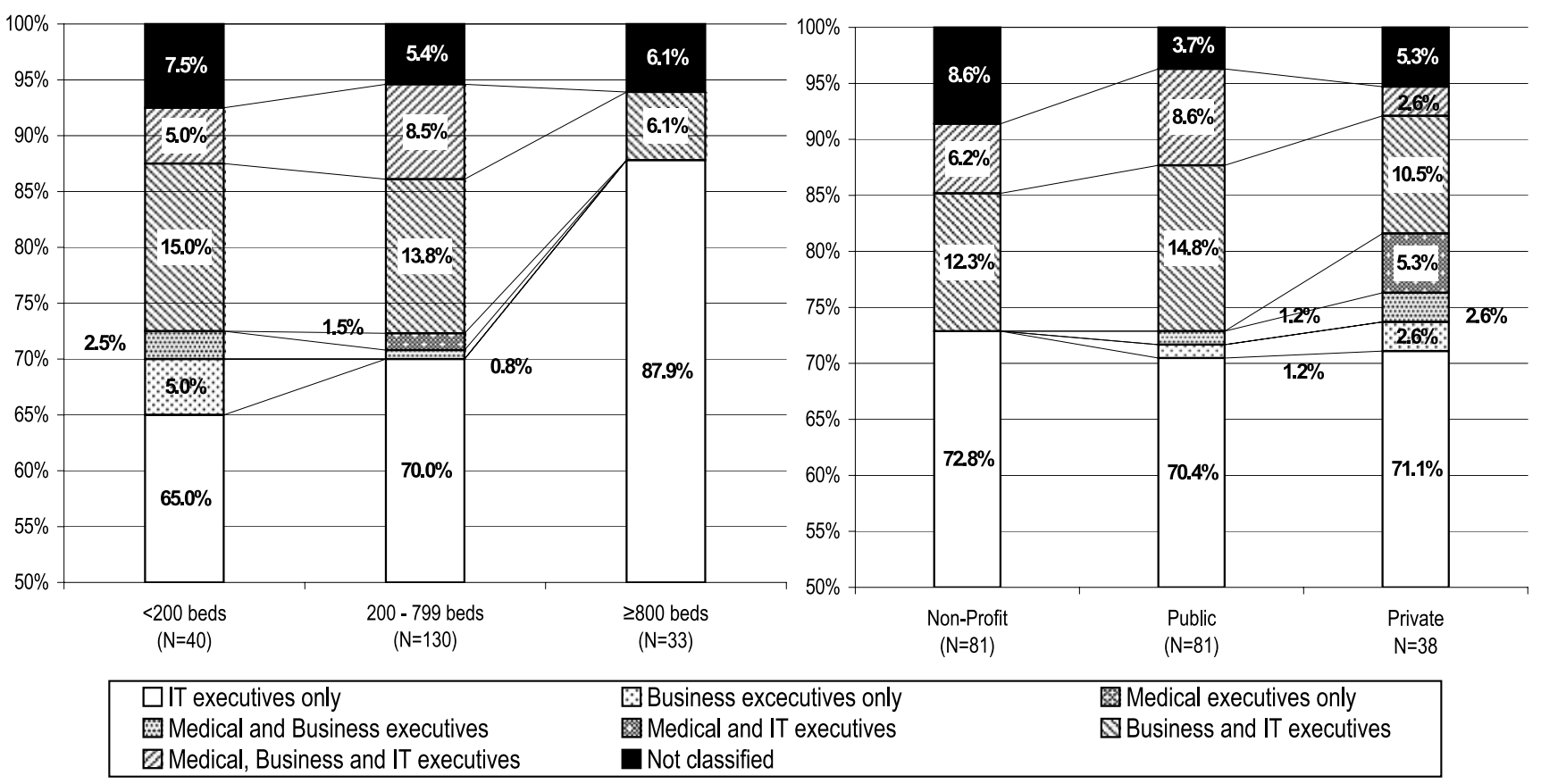

Fig. 3 Involvement in decisions concerning IT standards in the context of IT architecture

in hospitals are frequently involved in these decisions. In most cases, this results from decentralized organizational structures. German hospitals are typically divided into multiple hospital facilities and clinics. Due to the fact that IT is cross-functional, it is difficult to establish an appropriate balance between centralized and decentralized decisions. Therefore, the participating IT executives were queried as to which stakeholders (IT executives, medical executives and/or business executives) were involved in decisions on IT standards in the context of IT architecture (Fig. 3).

Our data suggest that in more than two-thirds of the considered hospitals IT standards in the context of IT architecture are exclusively set by IT executives (Fig. 3). With respect to the type of sponsorship of the hospitals, almost no difference can be found. In regard to the size, the data indicate some differences in decision structure: in $87.9 \%$ of large hospitals only IT executives are involved in decisions on IT standards in the context of IT architecture. By contrast, in only 65\% of small hospitals IT executives are exclusively involved in these kinds of decisions.

Therefore, in large hospitals the administrative executives are less often involved in the decision making process on IT standards compared to the decision making process in smaller hospitals. Medical executives in large institutions are not involved in the decision making process. The data suggest that IT executives are often solely responsible for complex application architectures and IT infrastructures. Thus, in big hospitals the responsibility for decisions in the context of IT architecture and infrastructure shifts towards IT executives. It is noteworthy that in private hospitals more than $5 \%$ of decisions are made alone or jointly by administrative and medical executives, without the participation of an IT executive. One explanation might be that in these hospitals the medical or administrative executives additionally fulfill tasks in the field of responsibility of IT executives.

\subsection{IT Infrastructure}

In a next step, participants were questioned on their deployed IT applications. These were considered separately for administrative and medical applications. In this context, administrative applications refer to modules and applications that are primarily used for administration and management tasks (e.g., reception of patients or health insurance accounting) and therefore support administrative processes in hospitals. Medical applications primarily support investigative and treatment processes, e.g., provision of medical data, such as X-ray images or results of medical pre-investigations. Figure 4 shows absolute numbers for deployed IT applications of all survey par- ticipants. We provided the participants with five options to answer the question item on the status of IT applications: in use, in planning, important to their hospital or not in use.

The data shows the wide distribution of IT applications for the support of business processes, Diagnosis Related Groups (DRG), as well as personnel and material administration. The widely-used applications for processing of case classifications in German hospitals can be explained by legal requirements in Germany. The fact that two hospitals in the data sample do not utilize IT applications for their core business processes results from planned updates of the specific IT applications in the according hospitals. The distribution of IT applications supporting business processes is based on the utilization of hospital information systems (HIS). HIS are customized Enterprise Resource Planning (ERP) systems that are adapted to the special administrative and medical processes of hospitals, e.g., the reception of patients and accounting with health insurance. Our findings suggest that IT applications for service planning and maintenance are less common but that a number of hospitals are planning to introduce this type of application in the future. Furthermore, $24.3 \%$ of all participants state that an IT application for the support of resource planning is currently planned. 
Fig. 4 Administrative applications

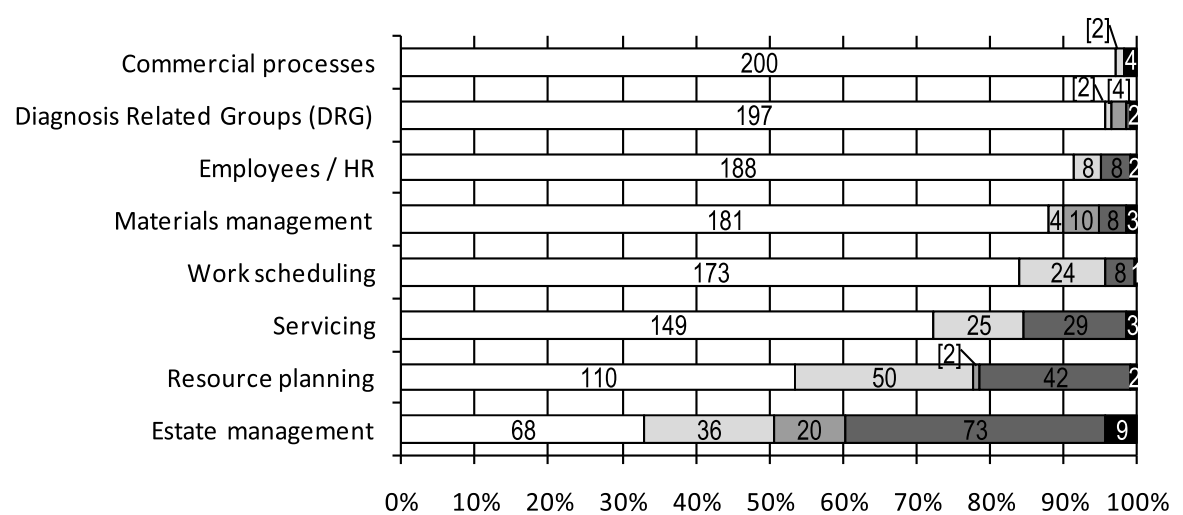

$\square$ In use $\quad \square$ Inplanning $\quad \square$ Important for us $\quad \square$ Not in use $\quad$ No entry

Fig. 5 Medical applications

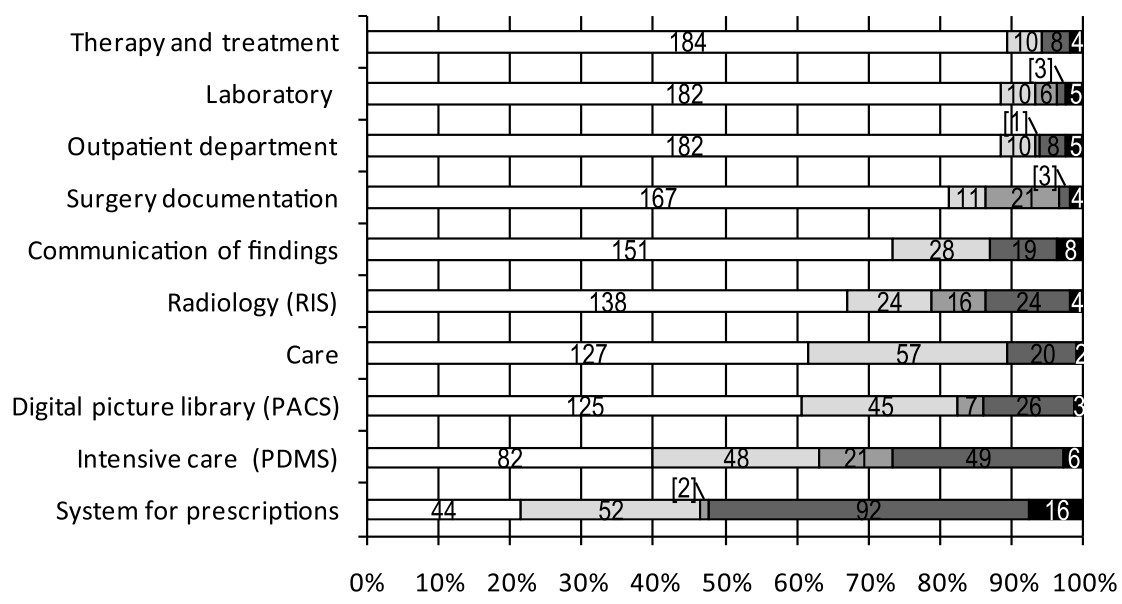

$\square$ In use $\quad \square$ Inplanning $\square$ Important for us $\quad \square$ Not in use $\quad$ No entry

Total $(\mathrm{N}=206)$

In comparison to Leimeister et al. (2008) who documented a prioritization of IT applications to support the legal introduction of DRG and case classifications, the prioritization of IT applications which are currently planned have shifted to applications that support the resource planning and real estate management. Consequently, it can be assumed that activities for the introduction of DRG are completed. The high percentage of planned administrative IT systems to support resource planning and real estate management tasks suggests that decision makers in German hospitals see a potential for improvement, e.g., shortening lead times and utilization of economies of scale. The increased activities in planning IT-based systems and applications to support care might be explained by aspired and necessary quality improvements in core health care services.
Figure 5 displays in use and planned medical IT applications. Our data suggest that applications for treatment, care and laboratory are the most widely-used applications. These applications have gained market saturation due to current or respectively planned use in over $90 \%$ of hospitals represented by participating IT executives. Applications for radiology, intensive care and surgery documentation are information systems which were only used by a minority of the participating hospitals. Their minor degree of distribution is probably related to the fact that these applications are not utilized in all hospitals, as they cover special medical procedures.

Additionally we can note a high number of IT applications to support the care and electronic picture archiving (PACS), which 57 respectively 45 of the participating hospitals are planning at the moment. The data suggests a similar planning activity for applications to support intensive care via Patient Data Management Systems (PDMS) and medication. PDMS are planned in 48 of the participating hospitals, and IT applications to support medication of patients in 52 of the participating hospitals.

\subsection{Business Requirements for IT}

Our survey results regarding business requirements for IT show that across all hospital sizes the optimization and standardization of work processes is the most important business requirement for IT (Fig. 6). Consequently, IT executives should have additional knowledge about the administrative and medical domains and processes. Further, IT executives in large hospitals discern those IT requirements that result in the realization of new business processes and development of new business segments to increase revenue to a significantly higher degree 
Fig. 6 Business requirements for IT compared by the size of the hospital
The use of IT helps the hospital in...

reducing costs.

implementing changes in workflows.

optimizing workflows.

realizing new workflows.

opening new business areas to increase revenue.

dealing with peak loads in treatment and care.

managing supplier relationships better.

standardizing workflows.

The use of IT helps the hospital in...

reducing costs.

implementing changes in workflows.

optimizing workflows.

realizing new workflows.

opening new business areas to increase revenue.

dealing with peak loads in treatment and care.

managing supplier relationships better.

standardizing workflows.
To what extent do you agree with the following statements?

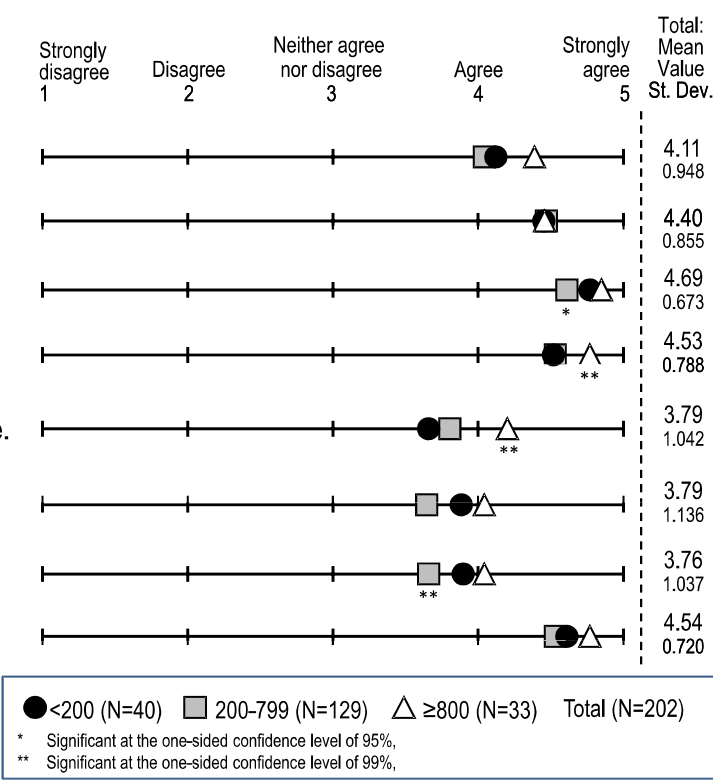

To what extent do you agree with the following statements?

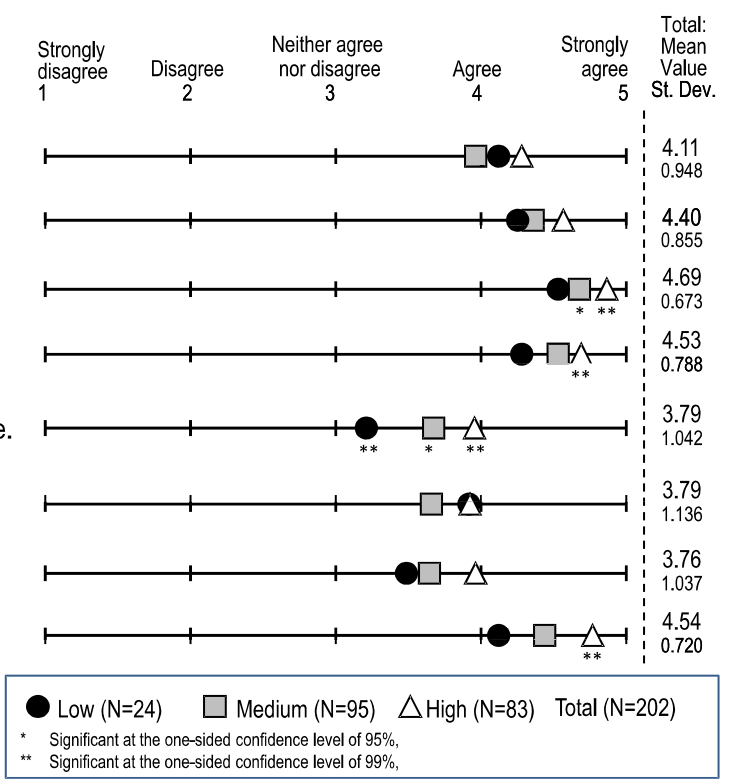

than do their colleagues in medium and small hospitals. We also found a relatively low valuation of IT requirements for the management and support of supplier relationships. A possible explanation can be seen in the large heterogeneity of suppliers and corresponding lowinstitutional standardization of (data) exchange formats. Additionally, the processes and structures of supply chain management are heterogeneous in the health care sector and unique for each hospital.

Subsequently, the results were compared according to the perceived value contribution of IT. We assume that the perception of the value contribution and IT requirements for the optimization and standardization of work processes, the implementation of new work processes, as well as the development of new business segments are positively correlated (Fig. 7).

In summary, IT executives who perceive a high value contribution of IT assess the requirements for IT from the business domain as being more important than do other IT executives. The conducted $t$-tests show significant differences between the groups on question items inquiring about the optimization and standardization of work processes, implementation of new business processes and development of new businesses segments to increase revenue. Therefore, we deduce that the assessment of IT as an enabler depends on the perception of the value contribution of IT.

\subsection{IT Investment and Prioritization}

\subsubsection{IT Budgets in German Hospitals}

The compilation of IT budgets in German hospitals was determined by asking participating IT executives to group their provided IT budgets into three categories. The first category represents the 
Fig. 8 Distribution of IT budgets by hospital size
Fig. 9 Distribution of IT budgets by the type of sponsorship

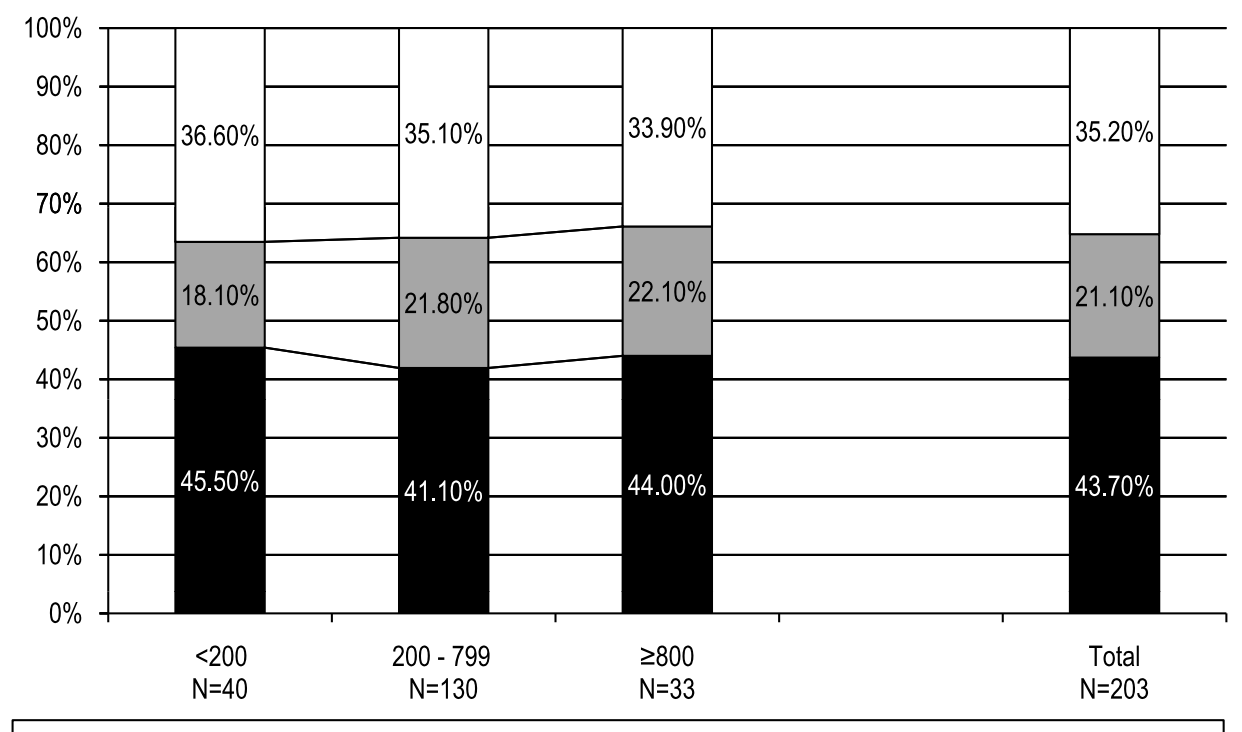

Operation of the relevant applications $\quad \square$ Projects (planning and development) $\quad \square$ Organization (staff, ...)

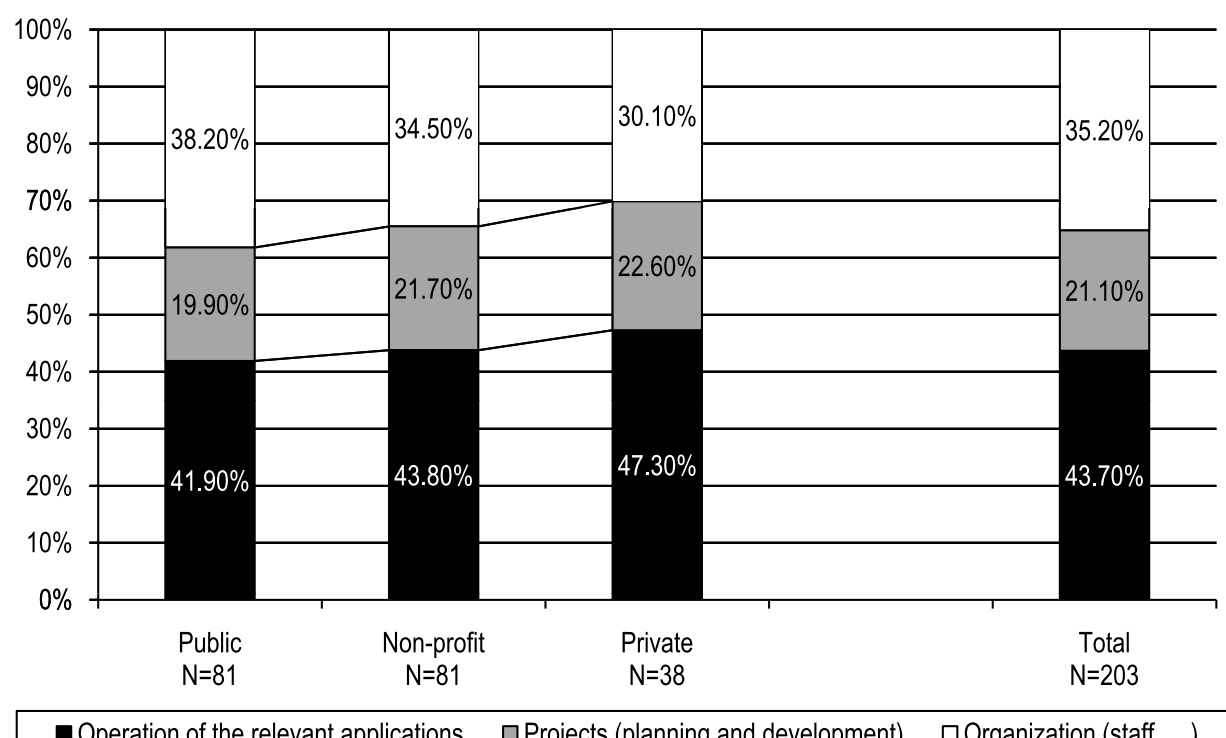

operation of "relevant IT applications", which covers the expenditures for the operation of existing applications. Shares of the IT budget that are spent on administrative activities are classified under the budget fraction "organization". In the category "projects", participating IT executives were asked to provide data about the components of IT budgets which were planned and allocated for the implementation of new IT projects (Fig. 8).

A comparison by hospital size reveals only minor differences in the distribution of IT budgets within the three categories. Nearly a third of IT budgets are allocated for activities concerning the organization, one fifth of IT budgets are allocated for the planning and development of new IT projects, and $45 \%$ of IT budgets over all hospital sizes are used for the operation of deployed IT applications.

Our data show a different allocation of IT budgets according to the type of sponsorship (Fig. 9). About 21.1\% of the available IT budget is allocated for implementation of new IT projects. The allocation of IT budgets concerning organizational items ranges between $30.1 \%$ in private and $38.2 \%$ in public hospitals. Consequently, in private institutions a significantly larger proportion $(47.3 \%)$ of IT budgets are allocated to the operation of IT applications compared to IT budgets for IT operation in non-profit institutions $(43.8 \%)$. We explain this by a higher diffusion of IT in private hospitals on the assumption that the operating costs in- crease with the number of utilized IT applications.

In summary, we conclude that $43.7 \%$ of the available IT budgets are spent for current operations of IT applications, while the data reveal small but statistically insignificant differences between hospitals that differ in type of sponsorship.

\subsubsection{Prioritization of Planned IT Investments}

Based on our data on operating and currently deployed IT applications, we were able to identify the five most widely used, as well as future investments on planned IT applications in German hospitals (Figs. 4 and 5). IT applications that support administrative processes show a very 
Table 4 Top five of in use and planned applications

\begin{tabular}{ll}
\hline Top 5 in use IT applications & Top 5 planned IT applications \\
\hline \$ Financial accounting & + Care \\
\$ Diagnosis Related Groups (DRG) & + Systems for prescriptions \\
\$ Human resources and wage accounting & \$ Enterprise Resource Planning (ERP) \\
+ Rehabilitation and treatment & + Intensive care \\
+ Laboratory plus outpatient department & + Electronic picture library \\
\hline
\end{tabular}

$\$=$ administrative IT application, $+=$ medical IT application

high degree of market diffusion. Three of the five most widely used applications support administrative tasks. These results corroborate findings by Leimeister et al. (2008) who documented that IT applications in hospitals are mainly used for billing and administrative tasks. However, we see a shift to investments in IT applications that support medical processes and tasks. Table 4 lists IT applications that are currently in use or in the planning phase.

\subsection{IT Decision Makers in German Hospitals}

For an effective and efficient utilization of IT, the IT strategy needs to be aligned- to the business strategy, and appropriate measures need to be derived from it (Henderson and Venkatraman 1993). IT executives need sufficient decision making power to maximize the value creation by the utilization of information and communication technology. Consequently, IT executives should posses the necessary support from management or be a part of the management team. This means the question is: What types of IT decision makers exist in German hospitals, and, in particular, what type of decision makers do the questioned IT executives expect in the future?

From previously conducted expert interviews we may presume that two types of IT decision makers will exist in Ger- man hospitals in the future. The first type of decision maker - the "IT manager" can be described as follows: IT managers include business objectives in the planning of IT, have adequate decision making powers, and receive the right to participate in strategic decisions. The second type of decision maker - the "system administrator" - shows a contrary picture: higher management pays less attention to system administrators and they do not seem equally involved in decisions of strategic and managerial importance, e.g., in contrast to IT managers, the system administrators do not possess the exclusive decision rights regarding IT budgets.

The responses to the future role of the IT decision makers were classified by a K-means clustering algorithm. The assumed two types of IT decision makers determined the number of clusters. The variables for the classification are the cluster variables shown in Fig. 10. The algorithm terminated after 14 iterations, as no changes in the clusters were found. Based on the responses to perspectives about the future role, the initial assumption concerning the two types of IT decision makers could be confirmed.

\section{Perspective on the future role of IT executives}

Cluster size

\section{Cluster variables}

Knowledge of medical procedures ***

Creative force for optimizing medical processes ***

Creative force for optimizing administrative processes ***

Planning and designing operational changes ***

Involvment in hospital's strategy ***

Coaching of employees ***

Creating value to operational result through the use of $\mathrm{IT}$ ***

Focus on technological issues

Involvement in decisions of the executive board or CEO ***
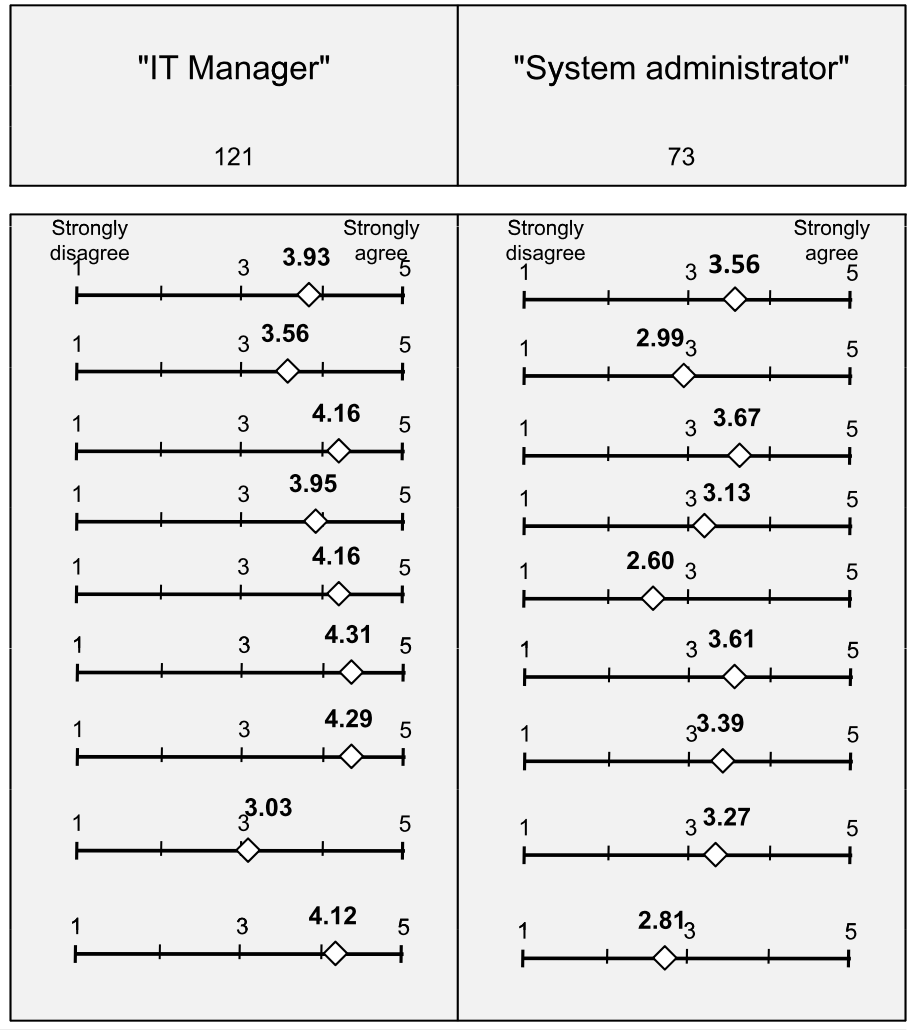

* Significant at the one-sided confidence level of $95 \%,{ }^{* *}$ Significant at the one-sided confidence level of $99 \%,{ }^{* \star *}$ Significant at the one-sided confidence level of $99.9 \%$

Fig. 10 Two types of IT decision makers and cluster variables 
Table 5 Characteristics of the future role of IT decision makers in German hospitals

\begin{tabular}{|c|c|c|c|}
\hline \multirow[t]{2}{*}{ Characteristics of cluster } & & \multicolumn{2}{|c|}{ Future role of top IT leaders } \\
\hline & & "IT manager" & "System administrator" \\
\hline \multirow[t]{4}{*}{ Age } & Mean & 46.37 & 44.61 \\
\hline & Younger than 35 & $5.78 \%$ & $12.32 \%$ \\
\hline & $35-50$ & $61.99 \%$ & 52.05 \\
\hline & \%Older than 50 & $24.79 \%$ & $27.40 \%$ \\
\hline \multirow[t]{2}{*}{ Gender } & Male & $86.77 \%$ & $90.41 \%$ \\
\hline & Female & $5.79 \%$ & $2.74 \%$ \\
\hline \multirow[t]{2}{*}{ Highest degree } & Vocational training & $22.31 \%$ & $35.62 \%$ \\
\hline & University & $66.11 \%$ & $54.79 \%$ \\
\hline \multicolumn{2}{|l|}{ Beds mean value (median) } & $611.37(480)$ & $456.92(330)$ \\
\hline \multirow[t]{3}{*}{ Size $^{\star}$} & $<200$ & $12.10 \%$ & $30 \%$ \\
\hline & $200-799$ & $67.74 \%$ & $58.57 \%$ \\
\hline & $\geq 800$ & $20.16 \%$ & $11.42 \%$ \\
\hline \multirow[t]{3}{*}{ Sponsorship } & Public & $42.15 \%$ & $36.99 \%$ \\
\hline & Private & $19.00 \%$ & $17.80 \%$ \\
\hline & Non-profit & $37.19 \%$ & $43.83 \%$ \\
\hline \multirow{3}{*}{$\begin{array}{l}\text { Decision-making authority } \\
\text { regarding IT investment }\end{array}$} & Only preparation & $19.01 \%$ & $28.76 \%$ \\
\hline & $\begin{array}{l}\text { Takes the decision up } \\
\text { to an amount }\end{array}$ & $64.46 \%$ & $58.90 \%$ \\
\hline & Takes the decision & $15.70 \%$ & $9.59 \%$ \\
\hline
\end{tabular}

Big differences were ascertained particularly for future cooperation in hospital strategy, and for involvement in the decisions of the board or higher management (Fig. 10). The IT manager sees his role as decision maker and as part of the management board and is involved in the definition of the hospital strategy.

An analysis of characteristics of both types of decision makers shows that the grouping depends significantly on the hospital size (Table 5). The larger the hospital, the more likely the IT decision maker sees himself in the role as IT manager. In contrast, the two decision maker types are distributed evenly among the various types of sponsorships for German hospitals.

A comparison of the educational level shows a significantly higher proportion of university graduates with IT managers. Additionally, regarding the discretionary competence in IT investments, IT managers enjoy greater freedom in decision making in comparison to system administrators. These differences are not statistically significant (ANOVA as a test for differences between the groups, marked by $*)$.

\section{Summary of Findings and Limitations of the Study}

The first objective of the underlying study was to document an inventory of IT governance structures in German hospitals with the help of a quantitative empirical survey. For this purpose, the study was aligned to the IT Governance Framework introduced by Weill and Ross (2005). The empirical results describe the current state of IT Governance in German hospitals. The second objective of this study was to identify possible future types of IT decision makers in German hospitals, as well as to describe and to compare their characteristics.

The key findings regarding IT governance and decision domains in German hospitals can be summarized as follows:

- There is a positive correlation between the perception of IT value contribution and the perceived potential of IT enabled business models in hospitals.

- The power of decisions in the domain of IT architecture depends on the size of the hospital: The larger the hospital, the more frequently the IT decision maker decides independently on relevant topics concerning the IT architecture.
- Our results suggest that hospitals are decreasing their investments in administrative applications and increasing their investments in medical applications.

- Main requirements for IT consist in the optimization and standardization of business processes.

- IT budgets in private hospitals contain the highest percentage share for deployed applications compared to nonprofit and public hospitals, and have the highest proportion of IT projects within the IT budget.

Two dominant types of future IT decision makers in German hospitals could be discovered through a cluster analysis. Grouping of types depends significantly on hospital size. In comparison to IT decision makers in smaller hospitals, IT decision makers in large hospitals differ in: their role as creative directors for the optimization of administrative and medical procedures, and the degree of their involvement in the hospital strategy, as well as involvement in decisions concerning strategic aspects. Interestingly, no differences between hospitals with different types of sponsorship could be documented.

The results of the study must be interpreted on the background of limitations. The study considered only the perspective of IT executives. Other perspectives, such as administrative or medical decision makers, were not specifically queried. Future studies could address different or similar expectations of the future role of IT managers from IT, administrative and medical executives. The collected data and derived findings represent only a snapshot; future survey studies should therefore be repeated to allow conclusions about trends of considered objectives of the study.

Future research efforts could additionally identify or prove possible causal relationships between discussed findings. Furthermore, the survey has not identified any performance measures for IT governance or characteristics of IT decision maker types in hospitals. Based on our results, various conditions, e.g., type of sponsorship or size of hospitals, and their possible effects on different implementations of decision making areas of IT governance could identify bestpractice configurations in German hospitals. We assume that a performance metric for effective IT governance in hospitals will become more important in the future. 


\section{Abstract}

Felix Köbler, Jens Fähling, Helmut Krcmar, Jan Marco Leimeister

\section{IT Governance and Types of IT Decision Makers in German Hospitals}

\section{An Empirical Study Among IT Decision Makers}

Growing expenses for health care services in hospitals stress the potential of a well applied IT governance for cost reduction, productivity gains and a possible source for competitive advantages. The underlying explorative study analyzes the current status of IT governance through a survey among 206 IT decision makers in German hospitals. The quantitative analyses show that the most important requirements of IT managers for IT are the optimization and standardization of processes, that IT investments shift from administrative to medical IT applications, and that private hospitals display relatively higher IT budgets than do non-profit or public hospitals based on financial turnover. Further, two types of future IT decision makers are empirically identified. The types differ regarding their future role as initiators for process optimization and regarding the degree of involvement in strategic decision making.

Keywords: IT governance, Hospital, Healthcare, IT decision makers, IT outsourcing
Further research is needed based on the identified relationship between the perception of the value contribution of IT and the utilization of IT to realize new and profitable business models. Fastgrowing investments in medical IT applications for medical processes and tasks raise new research questions regarding an increased progressive fusion of IT and medical technology (Schweiger et al. 2007; Mauro et al. 2008; Leimeister and Glauner 2008). Further research could help to understand and explain which role IT plays within the health care sector.

\section{References}

Anderson GF, Frogner BK, Johns RA, Reinhardt UE (2006) Health care spending and use of information technology in OECD countries. Health Affairs 25(3):819-831

Apkon M, Sighaviranon P (2001) Impact of an electronic information system on physician workflow and data collection in the intensive care unit. Intensive Care Medicine 27(1):122-130

Bernnat R (2006) Endbericht zur KostenNutzen-Analyse der Einrichtung einer Telematikinfrastruktur im deutschen Gesundheitswesen. Booz Allen Hamilton $\mathrm{GmbH}$, Düsseldorf

Blum K, Schilz P (2005) Krankenhaus Barometer - Umfrage 2005. Deutsches Krankenhausinstitut e.V., Düsseldorf

Bortz J, Döring N (2002) Forschungsmethoden und Evaluation: für Human- und Sozialwissenschaftler. Springer, Heidelberg

Borzekowski R (2002) Measuring the cost impact of hospital information systems: 1987-1994. Board of Governors of the Fed eral Reserve System, Washington

Crane RM, Raymond B (2003) Fulfilling the potential of clinical information systems. The Permanente Journal 7(1):62-67

Destatis (2009a) Bruttoinlandsprodukt 2007 für Deutschland. http://www.destatis.de/ jetspeed/portal/cms/Sites/destatis/Internet/ DE/Presse/pk/2008/Bruttoinlandsprodukt/ Pressebroschuere_BIP2007, property=file. pdf. Accessed 2009-11-16

Destatis (2009b) Gesundheitswesen. http:// www.destatis.de/jetspeed/portal/cms/ Sites/destatis/SharedContent/Oeffentlich/ Al/IC/Publikationen/Jahrbuch/Gesundheit, property=file.pdf. Accessed 2009-11-16

Destatis (2009c) Statistisches Bundesamt Deutschland - Gesundheit. http://www. destatis.de/jetspeed/portal/cms/Sites/ destatis/Internet/DE/Navigation/

Statistiken/Gesundheit/Gesundheit.psml. Accessed 2009-11-16

Fähling J, Köbler F, Leimeister JM, Krcmar H (2009) Wahrgenommener Wert von IT in Krankenhäusern - eine empirische Studie. In: Hansen HR, Karagiannis D, Fill HG (eds) Business Services: Konzepte, Technologien, Anwendungen. Österreichische Computer Gesellschaft, Wien, pp 709-719

Gesundheitsberichterstattung des Bundes (2009a) Krankenhäuser/Vorsorge- oder Reha-Einrichtungen, Anzahl und Aufenthalte. http://www.gbe-bund.de/oowa921install/servlet/oowa/aw92/WS0100/ XWD PROC?_XWD_92/3/XWD_CUBE.DRILL/_
XWD_118/D.922/50282. Accessed 200911-12

Gesundheitsberichterstattung des Bundes (2009b) Krankenhäuser/Vorsorge- oder Reha-Einrichtungen, Anzahl und Aufenthalte. http://www.gbe-bund.de/oowa921install/servlet/oowa/aw92/dboowasys921. xwdevkit/xwd_init?gbe.isgbetol/xs_start neu/321502448/41637448. Accessed 200911-12

Haas P (2005) Medizinische Informationssysteme und elektronische Krankenakten. Springer, Heidelberg

Hacker J, Schommer R (2004) Integration von Behandlungspfaden. In: Jähn K, Nagel E (eds) E-Health. Springer, Heidelberg

Henderson JC, Venkatraman N (1993) Strategic alignment: leveraging information technology for transforming organizations. IBM Systems Journal 32(1):472-484

Irving R, Nevo S (2005) 2005-2006 Report on I.T. in Canadian hospitals, current capabilities and upcoming acquisitions. Canadian Healthcare Technology, Thornhill

IT Governance Institute (2009) COBIT 4.1 Excerpt, IT Governance Institute. http:// www.isaca.org/AMTemplate.cfm?Section= Downloads\&Template $=/$

ContentManagement/ContentDisplay.cfm\& ContentID=34172, Accessed 2009-11-11

Jähn K, Nagel E (2004) e-Health. Springer, Heidelberg

Köbler F, Fähling J, Leimeister JM, Krcmar H (2009) How German hospitals govern IT - an empirical study. In: Proc European conference on information systems (ECIS 2009), Verona

Krcmar H (2009) Informationsmanagement, 5 th edn. Springer, Heidelberg

Lehmann TM (2005) Handbuch der medizinischen Informatik. Hanser, München

Leimeister JM, Klapdor S, Hörmann C, Krcmar H (2008) Eine empirische Untersuchung unter IT-Entscheidungsträgern, 2nd edn. Books on Demand, Norderstedt

Leimeister JM, Glauner C (2008) Hybride Produkte - Einordnung und Herausforderungen für die Wirtschaftsinformatik. WIRTSCHAFTSINFORMATIK 50(3):248-251

Mauro C, Leimeister JM, Sunyaev A, Krcmar H (2008) Zentrale Verwaltung von Gesundheitskarten im stationären Krankenhausumfeld. WIRTSCHAFTSINFORMATIK 50(6):489-499

Meyer M, Zarnekow R, Kolbe LM (2003) IT-Governance: Begriff, Status quo und Bedeutung. WIRTSCHAFTSINFORMATIK 45(4):445-448

Nahm R, Poston I (2000) Measurement of the effects of an integrated point-of-care computer system on quality of nursing documentation and patient satisfaction. Computers in Nursing 18(5):220-229

Piccoli G, Ives B (2005) Review: IT-dependent strategic initiatives and sustained competitive advantage: a review and synthesis of the literature. MIS Quarterly 29(4):747-776

Raymond B, Dold C (2002) Clinical information systems - achieving the vision. Kaiser Permanente Institute for Health Policy, Oakland

Riedel W (2006) Umfrageergebnis zur ITSituation in deutschen Krankenhäusern. Institut für Krankenhauswesen, Braunschweig

Sachs MA (2005) Transforming the health system from the inside out. Frontiers of Health Services Management 22(2):3-12

Schweiger A, Sunyaev A, Leimeister JM, Krcmar H (2007) Toward seamless healthcare with software agents. Communications of 
the Association for Information Systems (CAIS) 19:692-709

Statistisches Bundesamt Deutschland (2005) Gesundheitswesen, Grunddaten der Krankenhäuser. Wiesbaden, pp 3-10

Statistisches Bundesamt Deutschland (2009) Statistisches Bundesamt Deutschland GENESIS-Online. https://www-genesis. destatis.de/genesis/online;jsessionid=
5A682BA6AFA2547B661716EA8D2CADD0. tcggen2?operation=abruftabelleAbrufen\& levelindex=1\&levelid=1257953924104 \&index=3. Accessed 2009-11-11

Weill P (2004) Don't just lead, govern: how top-performing firms govern IT. MIS Quarterly Executive 3:1-17

Weill P, Ross JW (2004) IT governance: how top performers manage IT decision rights for superior results. Harvard Business School Press, Boston

Weill P, Ross JW (2005) A matrixed approach to designing IT governance. MIT Sloan Management Review 46(2):26-34

Witt P (2000) Corporate Governance im Wandel. Zeitschrift Führung und Organisation 69(3):159-163 